


\title{
Valores jurídicos en la Regulación Penal de la Competencia Desleal en Ecuador
}

\author{
DOI: https://doi.org/10.46398/cuestpol.3969.01 \\ Jorge Núñez Grijalva *
}

\section{Resumen}

En todos los ámbitos del mundo jurídico existen aspiraciones superiores que representan valores jurídicos a ser protegidos, de entre los cuales destacan la justicia, el bien común y la seguridad jurídica. El presente trabajo se propuso analizar si el Legislador Ecuatoriano, en su proceso de construcción y promulgación de la normativa penal reguladora de la competencia desleal, incorporó a la misma estos tres valores. De forma lamentable, los resultados muestran una aparente ausencia de los tres valores jurídicos en la ley penal, dejando a los operadores de justicia en desventaja ante la necesidad de controlar esta clase de delitos, y a la sociedad en espera de su cumplimiento. Mediante un ejercicio de hermenéutica jurídica, el estudio parte de un problema real en el sistema jurídico ecuatoriano regulatorio del delito de competencia desleal, el cual exige ser discutido en la búsqueda de que el Estado tome las medidas necesarias para solucionarlo.

Palabras clave: Competencia desleal en Ecuador; valores jurídicos; regulación penal de la competencia desleal; seguridad jurídica; hermenéutica jurídica.

Doctor en Ciencias Jurídicas (Pontificia Universidad Católica Argentina). Magister en Economía y Derecho del Consumo (Universidad de Castilla-La Mancha). Magister en Gestión Estratégica Empresarial (Universidad Técnica de Ambato). Abogado (Universidad Nacional de Loja). Profesor Titular de la Pontificia Universidad Católica del Ecuador Sede Ambato. Av. Manuelita Sáenz s/n, sector El Tropezón, Ambato- Ecuador. ORCID ID: https://orcid.org/oooo-0oo1-5335-116o. Email: jnunez@ pucesa.edu.ec

Recibido el 12/12/2020 Aceptado el 26/04/2021 


\title{
Jorge Núñez Grijalva \\ 22 Valores jurídicos en la Regulación Penal de la Competencia Desleal en Ecuador \\ Legal Values in the Criminal Regulation of Unfair Competition in Ecuador
}

\begin{abstract}
In all areas of the legal world there are higher aspirations, which represent legal values to be protected, like the justice, the common good and legal security stand out. The present work was proposed to analyze if the Ecuadorian Legislator, in its process of construction and promulgation of the criminal law regulating against the unfair competition, incorporated these three values into it. Regrettably, the results show an apparent absence of the three legal values in criminal law, leaving legal operators at a disadvantage in view of the need to control this type of crime and society, awaiting compliance. Through an exercise of legal hermeneutics, the study starts from a real problem in the Ecuadorian legal system of the criminal law against of the unfair competition, which demands to be discussed in the search for the State to take the necessary measures to solve this problem.
\end{abstract}

Key words: Unfair competition in Ecuador; legal values; criminal regulation of unfair competition; legal security; legal hermeneutics.

\section{Introducción}

Como resultado de las relaciones de intercambio en los mercados, en ocasiones se presentan actos de competencia desleal que están reñidos con la ley, la lealtad y las buenas costumbres mercantiles, siendo por tanto factibles de ser procesados jurídicamente en las vías administrativa, civil y penal. En el ámbito penal, constituye un requisito sine qua non que el acto a ser procesado se encuentre previamente tipificado en el texto de la ley, ya que caso contrario los operadores de justicia no pueden actuar, quedando probablemente los delitos de competencia desleal en la impunidad. Sin embargo, el que todos (o la mayor parte) de los posibles tipos penales relacionados a la competencia desleal, estén contenidos en el texto de la ley penal, depende de que el Legislador, al momento de redactar la misma, haya considerado la importancia de la presencia de los valores jurídicos de la justicia, el bien común y la seguridad jurídica, como aquellas grandes aspiraciones que la sociedad quiere alcanzar a través de la aplicación efectiva en su sistema normativo y axiológico. En este propósito, el presente trabajo se propuso determinar si el Legislador Ecuatoriano, en su proceso de construcción y posterior promulgación de la normativa penal reguladora de la competencia desleal, ha incorporado estos tres valores jurídicos en el marco legal, o si tal vez, estos no han sido considerados al momento de 
elaborar y expedir la Ley, dejando a los operadores jurídicos en desventaja ante la necesidad de controlar esta clase de delitos, y a la sociedad en espera de su cumplimiento.

Mediante una investigación de enfoque cualitativo, específicamente desarrollada en el marco de la hermenéutica jurídica se trataron los ángulos doctrinario y objetivo del problema planteado. Al decir de Bedoya (2011), esta postura interpretativa, critica las concepciones mecanicistas y acríticas en el campo de la aplicación del Derecho, en el ejercicio de la redacción de cuerpos normativos y en el ámbito de la investigación jurídica en general, bajo el supuesto de que en estos menesteres prevalecen o, deben prevalecer, los procedimientos propios de la racionalidad jurídica. Compartimos con Bedoya (2011), una idea de la hermenéutica en la cual no solo se sitúan los textos en los marcos de referencia de donde emergen y cobran significación; sino que también, revindicamos las subjetividades en todo el proceso de elaboración dogmática, aplicación e investigación del saber jurídico en tanto que factor protagónico de los procesos intelectivos del lenguaje y, en consecuencia, en toda la trama jurídica asumida como proceso social, del que emergen relaciones de poder, que en ningún caso son neutrales ni asépticas.

\section{Libre mercado y competencia desleal}

El mercado, escenario donde el presente estudio analiza la competencia desleal y su normativa reguladora en el ámbito penal, funciona tal y como lo dijo hace tres siglos Adam Smith: "No de la benevolencia del carnicero, del vinatero, del panadero, sino de sus miras al interés propio es de quien esperamos y debemos esperar nuestro alimento (1776:23).” Esta expresión desnuda la realidad de los intercambios comerciales, donde cada actor, "busca sólo su propio beneficio, pero en este caso como en otros una mano invisible lo conduce a promover un objetivo que no entraba en sus propósitos" (Smith, 1776:322), y de esta manera, sin quererlo, promueve a su vez el bienestar general. Con estas palabras, el autor pretendía explicar la ley de la oferta y la demanda, en la cual la libre competencia es el factor fundamental de la estructura económica de la sociedad, ya que significa la más clara manifestación de las libertades personales (Vidal, 2001: 64).

Como se colige, dentro del tema de estudio se puede decir que la competencia es algo connatural al mercado. Sin embargo, en ocasiones, esta competencia se realiza mediante la ejecución de actos que sobrepasan los límites permitidos por la "sana costumbre mercantil" y las leyes de un determinado lugar, lo cual la ubica dentro de la esfera de la competencia considerada desleal e ilegal, merecedora de ser procesada y sancionada por el sistema jurídico de un Estado determinado. A la luz de la historia 


\section{Jorge Núñez Grijalva

y sus resultados, es discutible si la liberalización de la economía generada mediante la globalización de mercados ha proporcionado prosperidad general y una vida feliz y plena a todas las personas, tal como en su momento lo cuestiona (Samuelson y Nordhaus, 1998:3), llegando más bien a convertirse en un problema de nuestro tiempo (Stiglitz, 2002: 314). Lo cierto es que este nuevo nivel de competencia global ha generado profundos cambios en las relaciones mercantiles, haciéndolas más propensas a la presencia de actos considerados de competencia desleal.

Para Otamendi, la competencia en un mercado representa la lucha por la clientela, y cuando esta competencia es desleal, pasa a convertirse en un acto ilícito que, de estar tipificado como tal en la legislación, "alcanza la categoría de delito (1998: 1)". De otra parte, para Tapia es común que en los sistemas comerciales se permita y favorezca la competencia, "incluso aquella fuerte o ruda" (2008: 181), la cual sin embargo en ningún caso puede llegar a ser sucia o desleal. De lo mencionado, la competencia desleal puede ser definida como el conjunto de acciones que, en su ejecución, no respetan las normas jurídicas y los usos y costumbres honestas y generalmente aceptadas en el ámbito comercial de una determinada sociedad.

Respecto a la regulación internacional de la competencia desleal, el (Convenio de París, 1979: Art. 10, num. 2)² determina que "constituye acto de competencia desleal todo acto de competencia contrario a los usos honestos en materia industrial o comercial," mientras que a nivel nacional, la (Ley Orgánica de Regulación y Control del Poder de Mercado, 2014: Art. 25) conceptualiza como desleal "todo hecho, acto o práctica contrarios a los usos o costumbres honestos en el desarrollo de actividades económicas, incluyendo aquellas conductas realizadas en o a través de la actividad publicitaria...". Respecto a lo que se entiende por usos y costumbres honestos en el ejercicio del comercio, la (Superintendencia de Industria y Comercio de Colombia-SIC, Concepto 01086015, núm. 2, 2001: 1), considera que estos podrían verse como aquellos "principios morales y éticos" que deben ser cumplidos por los comerciantes y demás participantes de la actividad competitiva en los mercados, teniendo presente en este contexto que su observancia constituye una práctica usual.

\subsection{Principales actos de competencia desleal y su efecto}

La Organización Mundial de Propiedad Intelectual (en adelante OMPI) ha analizado en profundidad el fenómeno de la competencia desleal. En uno de sus estudios, realizado por (OMPI, Protección contra la competencia desleal, análisis de la situación mundial actual, 1994: 29), se dice que un acto que se considere desleal, con frecuencia "surge en circunstancias complejas

2 El Convenio de París es la más antigua norma internacional de propiedad industrial, y de regulación de la competencia desleal. Fue creada en el año de 1883, y luego de varias actualizaciones (la última en 1979), se mantiene en vigencia bajo la administración de la OMPI. 
que exigen de escrutinio y juicio basados en las normas establecidas o existentes (...)", ante lo cual también se debe considerar el hecho que toda categorización o clasificación que se haga en este tema posee un cierto grado de traslape entre todos los conceptos y categorías empleadas. De esta manera, el estudio de la OMPI establece dos categorías generales de los actos de competencia desleal: i) los actos que están tipificados en el Convenio de París; y, ii) otros actos no tipificados por este convenio.

En relación con la primera categoría, esta toma como base el (Convenio de París, 1979: Art. 10 bis, núm. 3), el cual dispone que, de manera particular, deberán prohibirse los siguientes actos:

1. cualquier acto capaz de crear una confusión, por cualquier medio que sea, respecto del establecimiento, los productos o la actividad industrial o comercial de un competidor; 2. las aseveraciones falsas, en el ejercicio del comercio, capaces de desacreditar el establecimiento, los productos o la actividad industrial o comercial de un competidor; 3 . las indicaciones o aseveraciones cuyo empleo, en el ejercicio del comercio, pudieren inducir al público a error sobre la naturaleza, el modo de fabricación, las características, la aptitud en el empleo o la cantidad de los productos.

Respecto a la segunda categoría, con efecto general el estudio de la OMPI incluye otros actos adicionales, que a pesar de no estar tipificados en el supra citado Art. 1obis, núm. 3), han sido reconocidos por los diversos tribunales de justicia a nivel internacional como actos de competencia desleal, y que cada vez más, están siendo materia de regulaciones normativas nacionales. Estos actos son los siguientes: a) violación de los secretos empresariales; b) aprovechamiento injusto del esfuerzo ajeno; c) publicidad comparativa; d) otros actos diversos considerados de competencia desleal, como pueden ser: i) acoso publicitario, explotación del miedo, presión psicológica indebida; ii) promoción de ventas: primas, regalos, loterías, etc.; iii) obstrucción de las actividades de mercado; iv) incitación para alejar los clientes de los competidores; v) inducir al personal o agentes de los competidores a rescindir sus contratos de empleo o sus contratos comerciales.

Como efecto común ocasionado por los diversos actos de competencia desleal, en lo principal se genera la afectación a los derechos de todas las personas en general y, de manera particular, de los competidores y consumidores involucrados en los actos de intercambio en el mercado. Frente a esto, la teoría del abuso del derecho plantea la necesidad de proteger el equilibrio entre los derechos individuales y los derechos colectivos, de tal manera que la convergencia de ellos permita el restablecimiento de los derechos con la función social, ya que estos actos alteran el equilibrio y la libertad competitiva en el comercio, precisamente por el desborde de los límites personales (Negrete, 2016). 


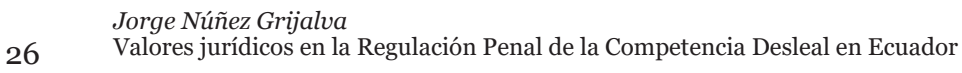

\section{Marco jurídico penal vigente en Ecuador regulatorio de los actos de competencia desleal}

El Código Orgánico Integral Penal ecuatoriano (en adelante COIP), tipifica como delito diversas prácticas que son susceptibles de asimilarse a los actos de competencia desleal contenidos en la normativa relativa al Derecho de Competencia. Al respecto, este código regula los actos de competencia desleal, dividiéndolos en tres ámbitos de posible infracción penal, a saber:

\subsection{En lo relativo a los delitos contra el derecho a la propiedad}

El (COIP, 2014: Art. 208 A), tipifica el delito de falsificación de marcas y piratería lesiva contra los derechos de autor, disponiendo que la persona que, "fabrique o comercialice, a escala comercial, mercancías o su envoltorio que lleven puesta, sin la debida autorización, una marca idéntica a la válidamente registrada para tales mercancías o que esa marca no pueda distinguirse en sus aspectos esenciales", será sancionada pecuniariamente mediante la siguiente escala: i) cuando el valor de la mercadería incautada se encuentre en el rango de 142 a 424 salarios básicos unificados del trabajador en general (en adelante $\mathrm{SBUTG}^{3}$ ), se aplicará una multa de 55 a 85 SBUTG; ii) cuando el valor de la mercadería incautada sea mayor a 424 y menor a 847 SBUTG, se aplicará una multa de 86 a 175 SBUTG; y, iii) cuando el valor de la mercadería incautada sea mayor a 847 SBUTG, se aplicará una multa de 176 a 295 SBUTG.

Y continúa el mismo Art. 208 A, el cual en su segundo párrafo enfatiza que:

La misma pena se aplicará a la persona que produzca, reproduzca o comercialice a escala comercial, mercancía pirata que lesione el derecho de autor para las obras registradas o no, entendiéndose estas como cualquier copia hecha sin consentimiento del titular del derecho de autor o de una persona debidamente autorizada por él. Las disposiciones precedentes no se aplicarán a bienes o productos que no tengan un fin comercial. En el caso de las marcas notorias, no se requerirá que el titular del derecho demuestre que la marca está válidamente registrada, sino únicamente su derecho como titular. Cuando una persona jurídica sea la responsable, será sancionada con las mismas multas y su extinción. No constituye delito la fabricación o comercialización de mercancías imitadas que tengan una marca con características propias que no conlleven a una confusión con la marca original, sin perjuicio de las responsabilidades civiles a que haya lugar.

3 A la fecha de redactar el artículo (diciembre de 2017), en Ecuador el Salario Básico Unificado del Trabajador en General, es de 375 dólares de los Estados Unidos de América. Al momento (agosto 2020), este valor es de 400 dólares. 
Como se observa, el supra citado artículo solo tipifica como delitos contra el derecho a la propiedad, dos clases de actos de competencia desleal, relacionados a: i) la falsificación de marcas; y ii) los actos relacionados a la piratería lesiva contra los derechos de autor.

\subsection{En lo relativo a los delitos contra los derechos de los consumidores, usuarios y otros agentes del mercado}

El (COIP, 2014: Art. 235), tipifica el delito de engaño al comprador respecto a la identidad o calidad de las cosas o servicios vendidos, disponiendo que:

La persona que provoque error al comprador o al usuario acerca de la identidad o calidad de la cosa o servicio vendido, entregando fraudulentamente un distinto objeto o servicio ofertado en la publicidad, información o contrato o acerca de la naturaleza u origen de la cosa o servicio vendido, entregando una semejante en apariencia a la que se ha comprado o creído comprar, será sancionada con pena privativa de libertad de seis meses a un año. Si se determina responsabilidad penal de una persona jurídica, será sancionada con multa de diez a quince salarios básicos unificados del trabajador en general.

En el supra citado artículo, se observa que el COIP incluye como tercer tipo penal regulado, la generación de confusión en el consumidor (respecto a la identidad o calidad de las cosas o servicios vendidos), lo cual a su vez podría conllevarlo a errar en el momento de tomar su decisión de compra. Como se ha observado, la norma penal tipifica solo tres actos de competencia desleal factibles de ser procesados penalmente, por lo que es notoria la existencia de insuficiencia normativa al respecto, ya que esta Ley no tipifica de manera completa la mayor parte de prácticas de esta clase contenidas en las normas nacionales o internacionales pertinentes, dejando al Estado y a los posibles particulares afectados, sin la posibilidad real de que estos últimos puedan llevar adelante el ejercicio de la acción penal en defensa de sus derechos, situación ciertamente compleja ya que como bien sabemos, si las infracciones a un determinado marco jurídico no pueden ser sancionadas adecuada y oportunamente, es posible que sobrevenga un clima de impunidad, el cual lastima el Estado de Derecho y a todos quienes habitan en él.

Con efecto ilustrativo de lo antes mencionado, la (Ley Orgánica de Regulación y Control del Poder del Mercado de Ecuador, 2011: Art. 27), tipifica 29 diversas acciones consideradas prácticas desleales, por lo que sería simplemente lógico que las dos normas ecuatorianas guardasen concordancia entre sí, y de esta forma el COIP tipifique las mismas 29 acciones de competencia desleal, permitiendo un tratamiento integral del tema y evitando el aparecimiento de la impunidad. 
Jorge Núñez Grijalva
28 Valores jurídicos en la Regulación Penal de la Competencia Desleal en Ecuador

\section{Axiología: marco de estudio de los valores jurídicos}

En la búsqueda de una mejor comprensión de la importancia de los valores jurídicos en las diversas interacciones sociales, es necesario recordar que la Axiología es la disciplina filosófica que se encarga del estudio de los valores y su esencia. El desarrollo científico de la Axiología formal se debe principalmente al trabajo de (Hartman, 1973) quien desarrolló la ciencia de la Axiología entre 1930 y 1973, pretendiendo entender cómo piensan las personas e identificar ciertos patrones generales de pensamiento (y por lo tanto de comportamiento) de los seres humanos. En este sentido, desarrolló principalmente su trabajo filosófico, buscando responder a la pregunta fundamental “¿qué es el bien?”, conceptuando al mismo de tal forma que, "pudiera ser organizado para ayudar a preservar y enriquecer el valor de la vida humana" (1973: s/p). De esta forma, este investigador encontró la respuesta a su modo de ver en el axioma sobre el que basó su ciencia de la Axiología, al decir que, "una cosa es buena cuando se ajusta al sentido de su concepto (Hartman, 1973: s/p)"

Es así que llegamos a la Axiología jurídica, dominio filosófico que estudia los valores jurídicos, descubriendo y explicando -al menos en teoría - cuáles deberían ser aquellos que tornarán correcto un modelo de Derecho, o que primarán a la hora de elaborar o aplicar el Derecho. Por lo demás, destaca la posición del filósofo norteamericano John Rawls, quien redefinió a la Axiología Jurídica como la Teoría de la Justicia, término con el que bautizó su obra cumbre, en la cual procura resolver el problema de la justicia distributiva mediante el uso de una variante del contrato social.

Para (Rawls, 1999:12), el más importante de los valores jurídicos es precisamente el de la justicia, dada su trascendencia e impacto en la vida social. Para este autor, la justicia como justicia comienza con una de las acciones más generales que puede hacer toda sociedad, esto es, "con la elección de los primeros principios de una concepción de justicia que regule todas las críticas posteriores y la reforma de las instituciones." 4 De esta forma, cuando la sociedad ha elegido su propia concepción de la justicia, está en posición para definir colectivamente una constitución y una legislatura para promulgar las diversas leyes que necesite, pero siempre observando los principios de justicia inicialmente acordados en los orígenes de su contrato social.

La sinopsis axiológica desarrollada hasta aquí, utilizando el valor jurídico de la justicia como ejemplo, cumple el propósito de remarcar la importancia que tienen los valores jurídicos para la vida de una sociedad. Por esta razón,

4 Texto original en inglés, tomado de RAWLS, John, 1999: p. 12: “Justice as fairness begins, as I have said, with one of the most general of all choices which persons might make together, namely, with the choice of the first principles of a conception of justice which is to regulate all subsequent criticism and reform of institutions" (traducción propia). 
es de relevancia para el análisis jurídico el determinar si existe presencia (o ausencia) de los valores de la justicia, bien común y seguridad jurídica, en la normativa regulatoria del fenómeno de la competencia desleal en el país, en este caso en particular dentro del ámbito penal.

El propósito perseguido es el de generar criterios válidos que fortalezcan o incorporen la presencia de los mencionados valores jurídicos, en las normas positivas pertinentes. Por supuesto, esta incorporación debería implementarse a nivel general dentro del espíritu de la ley, ya que resultaría inadecuado (y hasta peligroso) que los valores jurídicos sean positivizados, es decir, reducidos al simple texto impreso de la ley, pretendiendo haber superado sus características de ser universales, abstractos, a históricos e inmutables, pasando simplemente a ser "objeto de estudio de la teoría del derecho encargada del derecho que es, cuando su análisis corresponde al derecho que debe ser" (Estrada, 2011: 49).

No se debe perder de vista que los valores jurídicos tratan de materializar el cumplimiento del valor justicia (como máximo valor del sistema jurídico), mostrando con claridad la importancia que la justicias tiene para una sociedad, la cual se materializa a través de la aplicación adecuada de la ley. Sin embargo, una vez positivizados los valores jurídicos habrán perdido en gran medida esa capacidad de guiar y orientar hacia la consecución de la justicia a todos quienes tienen contacto con la ley, desde el legislador que la crea hasta los ciudadanos sujetos a ella, pasando por los diversos operadores del sistema jurídico que la aplican.

\section{Presencia de los valores jurídicos de la justicia, seguridad jurídica y bien común, en la normativa penal ecuatoriana regulatoria de la competencia desleal}

Para Portela, los valores jurídicos son, "cualidades, finalidades que el Derecho ha de conseguir para ser considerado plenamente tal" (2008: 62), facilitando de esta manera su correcto funcionamiento dentro del orden social. Existen diversos valores jurídicos, algunos de ellos considerados tradicionales, como pueden ser el orden, la paz, la seguridad, la justicia, la libertad y el bien común. No obstante, en vista que los efectos dañosos de la competencia desleal son capaces de lesionar a toda la sociedad, el presente estudio toma para su análisis los valores de la justicia, el bien común y la seguridad jurídica, debido al amplio impacto que estos valores causan en la sociedad, sea con su presencia o ausencia, dentro de las normas positivas y la realidad social en sí. 
Jorge Núñez Grijalva
$30 \quad$ Valores jurídicos en la Regulación Penal de la Competencia Desleal en Ecuador

\subsection{La justicia}

La justicia es considerada la virtud cardinal del Derecho, la que retribuye a cada uno lo que por derecho le corresponde. La justicia tiene carácter abstracto, debido a que es un ente ideal que causa satisfacción cuando creemos que la misma se ha cumplido y, nos causa molestia cuando creemos lo contrario; en otras palabras, es una regla de armonía, de igualdad proporcional, distributiva entre lo que se da y lo que se recibe en las relaciones entre individuos. El problema no está en la idea de justicia, sino en los criterios para su medición, en las pautas de valoración de las realidades que deben ser igualadas. Por supuesto, en este sentido es fundamental saber cuál es el criterio para establecer la verdadera equivalencia, una que sea precisamente 'justa' y adecuada.

Respecto al vínculo de la justicia con el sistema normativo, en Moral a Nicómaco interpretado por (De Azcárate, 1873: 123), Aristóteles piensa que "la justicia de las acciones está de ordinario de acuerdo con su legalidad", lo cual se puede llevar a la práctica mediante dos posibles formas de concebir la justicia: como legalidad y como igualdad. En el primer caso, una acción es justa si se realiza conforme a las leyes; y en el segundo caso, una acción es justa cuando se establece y perdura una relación de trato igualitario.

Por su parte, la Instituta ${ }^{5}$ creada por orden del emperador romano Justiniano I, inicia con la siguiente frase: "iustitia est constans et perpetua voluntas ius hum cuique tribuendi," la cual ilustra con total claridad la trascendental función que le ha sido asignada a la justicia en las antiguas normas romanas de Derecho. Además, colabora a entender la razón por la cual la Axiología la considera el valor jurídico más importante de todos, debido a que el resultado del accionar conjunto de todos los demás valores, en realidad, solo trata de materializar la real consecución de la justicia.

En la época contemporánea, siglos XX y XXI, diversos filósofos han aportado su contribución al mejor entendimiento de la justicia, como por ejemplo Kelsen, para quien la justicia es "aquello bajo cuya protección puede florecer la ciencia y, junto con la ciencia, la verdad y la sinceridad," (1991: 120), o como Rawls (1958), quien define su ya mencionada teoría de la justicia en términos de justice as fairness, ubicando a la equidad como el valor que debe presidir la justicia, donde Rawls mira a la equidad como la existencia de un acuerdo recíproco entre los seres humanos, particular visión que para Puyol representa el haber materializado un trato, en el que,

5 La Instituta (Instituciones) fue creada con el propósito de contar con un tratado elemental de Derecho, que permita la enseñanza de la disciplina a la juventud deseosa de estudiar las leyes. Formaba parte del Corpus Iuris Civilis, de Justiniano I, y fue promulgada el 21 de noviembre de 533, adquiriendo fuerza de ley el 30 de diciembre del mismo año. Consultar en las referencias biográficas Kriegel y Kriegel (1889).

6 En castellano: justicia es la constante y firme voluntad que dar a cada uno su derecho. 
"todas las partes sientan que la diferencia entre lo que dan a los demás y que reciben de ellos es adecuada o justa" (2004: 124).

Cabe precisar que el valor de la justicia tiene diferente connotación dependiendo del paradigma de quien lo mire. De esta manera, para la corriente iuspositivista por ejemplo, el valor de la justicia se cumplirá en la medida que el texto de la ley sea respetado; mientras que por otro lado, para el iusnaturalismo, el valor de la justicia se materializará cuando en cada caso puntal sean respetados aquellos valores superiores. Es así que dentro del dilatado debate entre estas dos visiones filosóficas del Derecho $\mathrm{y}$, a manera de una posición intermedia, ha tenido gran connotación el aporte de John Finnis, quien propone la existencia de un iusnaturalismo no enfrentado al positivismo jurídico.

Finnis, comentado por el español (Rodríguez - Toubez, 1993: 386387), de manera ciertamente ecléctica, plantea una justicia enfocada en alcanzar el bien común, el cual una vez distribuido en toda la comunidad le permite a cada integrante alcanzar una vida plena y de bienestar, lo que tiene concordancia con la (Constitución de la República del Ecuador, 2008: Art. 3, núm. 5), la cual pretende que todos los ciudadanos puedan alcanzar el tan anhelado estado de bienestar denominado "buen vivir." La visión de este autor es comentada por Hart, para quien la interpretación flexible del iusnaturalismo de Finnis, "es en muchos aspectos complementaria más que rival de la teoría jurídica positivista” (1983: 10).

\subsection{El bien común}

Este valor es considerado otro de los fines del Derecho, ya que abarca el conjunto de las condiciones de la vida social, necesarias para que los seres humanos puedan vivir a plenitud. Es necesario recordar que el Derecho tiene como objeto regular la actividad individual y permitir la vida en sociedad, la que busca un fin que es común de todos los integrantes del grupo social. No es de menor importancia, decir que no se puede concebir norma alguna integrante del sistema jurídico que tenga como objeto el alcance de un fin individual, ya que todas deberían permitir alcanzar el bien de todos, es decir, el bien común en tanto que dispositivo básico para la edificación intersubjetiva de los espacios de convivencia ciudadana.

Esta percepción abiertamente humanista, originada en los antiguos pensadores griegos, principalmente en Platón y Aristóteles, fue fortalecida y arraigada gracias al trabajo filosófico de quien es considerado su más grande representante: Tomás de Aquino. Es así que Tomás de Aquino, abordó el tema en su obra "Suma Teológica", cuando al referirse a la esencia de la ley afirmaba que esta no es más que "una prescripción de la razón, en orden al bien común, promulgada por aquel que tiene el cuidado de la comunidad» (1225-1274: s/p). Esta posición generó gran impacto en la visión de la 
Iglesia Católica respecto al bien común, generando consecuencias en su pensamiento que se evidenciaron, por ejemplo, en la encíclica Rerum Novarum, ${ }^{7}$ mediante la cual se construyó la conocida Doctrina Social de la Iglesia, en cuyo Compendio se entiende al bien común como, "el conjunto de condiciones de la vida social que hacen posible a las asociaciones y a cada uno de sus miembros el logro más pleno y más fácil de la propia perfección" (Pontificio Consejo de Justicia y Paz, 2004 s/p).

Para esta concepción, el bien común no es la suma de los bienes de cada uno de los miembros de la sociedad, ya que ese bien es indivisible, y solo con la colaboración de todos puede ser alcanzado, aumentado y protegido. E incluso va más allá, exigiendo cuidado y prudencia por parte de cada uno y, de manera especial, de aquellos que ejercen la autoridad, en clara alusión a lo que hoy conocemos como los Estados nacionales y sus sistemas jurídicos y políticos.

Muchas de las posiciones de Rerum Novarum fueron completadas por encíclicas posteriores, entre ellas la Mater et Magistra, en la cual el (Papa Juan XXIII, 1961: s/p) señalaba que, "en la época actual se considera que el bien común consiste principalmente en la defensa de los deberes y derechos de la persona humana" (Pontificio Consejo de Justicia y Paz, 2004 s/p). ${ }^{8}$

Evidentemente con el paso del tiempo y el fin de la tradición escolástica, el concepto del bien común sufrió diversos cambios, en razón de la puesta en escena de nuevas realidades políticas, económicas y sociales. Al respecto, Michelini manifiesta que para no pocos pensadores, "el concepto de bien común recobra un nuevo sentido en el ámbito político y jurídico con la teoría del contrato social (Hobbes, Locke) (2007: s/p)", lo que configura el contexto actual en el cual el hombre, mediante su actividad cotidiana, procura ser el artífice de su propia superación; empero, dado que vive en sociedad, no puede alcanzar sus fines individuales si estos no se adecúan a

7 Rerum Novarum fue la primera encíclica social de la Iglesia Católica, promulgada por el Papa León XIII, el 15 de mayo de 1891. Consiste en una carta abierta dirigida a todos los obispos y catedráticos, relacionada a las condiciones de las clases trabajadoras, en la cual el Papa mostraba su apoyo a los derechos laborales y, al mismo tiempo, ratificaba el derecho que tienen las personas a la propiedad privada. Además, analizaba las relaciones existentes entre el gobierno, las empresas, los trabajadores y la Iglesia, proponiendo una nueva organización socioeconómica. Rerum Novarum fundó los principios para buscar la justicia social en la economía y la industria, siendo una piedra fundamental para la posterior construcción de la actualmente conocida Doctrina Social de la Iglesia. Fuente: Pontificio Consejo justicia y Paz, 2004. Compendio de la doctrina social de la Iglesia, núm. 164, El principio del bien común. Ciudad de El Vaticano. Disponible en línea. En: http://www.vatican.va/roman_curia/ pontifical_councils/justpeace/documents/rc_pc_justpeace_doc_20060526_compendio-dott-soc_ sp.html\#Significado\%20y\%20aplicaciones\%2oprincipales. Fecha de consulta: $\overline{1}$ de julio de 2017.

8 La encíclica Mater et Magistra (madre y maestra), relativa al desarrollo de la cuestión social a la luz de la doctrina cristiana, fue publicada en Roma, el 15 de mayo del año 1961, por orden del Papa Juan XXIII y está presente en el compendio. Fuente: Pontificio Consejo justicia y Paz, 2004. Compendio de la doctrina social de la Iglesia, núm. 164, El principio del bien común. Ciudad de El Vaticano. Disponible en línea. En: http://www.vatican.va/roman_curia/pontifical_councils/justpeace/documents/rc pc_justpeace_doc_20060526_compendio-dott-soc_sp.html\#Significado\%20y\%20aplicaciones\%20 principales. Fecha de consulta: 1 de julio de 2017. 
los esquemas que le impone la misma sociedad. De esta manera, el hombre no puede actuar en la búsqueda de su propio bien individual y del bien común, sin considerar (y acatar) la conducta que, a través del Derecho y su sistema normativo, se le pide observar de manera generalmente obligatoria.

\subsection{La seguridad jurídica}

Esta constituye una garantía que el Estado le otorga a cada ciudadano, de que su persona, bienes y derechos, no serán violentados; o de que, si esto llegara a producirse, el Estado y la sociedad aseguran la protección y reparación de estos. En otras palabras, la seguridad jurídica es una garantía de Derecho que tiene cada individuo, relativa a que su situación jurídica no será modificada más que por procedimientos regulares y conductos legales establecidos, previa y debidamente publicados y, respetando el debido proceso y el derecho a la defensa que tiene toda persona en un Estado de Derecho.

En el sistema constitucional ecuatoriano, la seguridad jurídica es considerada como un derecho público, subjetivo, reconocido por la Constitución de la República, cuando en su Art. 82 dispone taxativamente que, "el derecho a la seguridad jurídica se fundamenta en el respeto a la Constitución y en la existencia de normas jurídicas previas, claras, públicas y aplicadas por las autoridades competentes. "Al respecto del reconocimiento constitucional del derecho a la seguridad jurídica, para Zavala, tal reconocimiento no significa otra cosa que "calificar a la seguridad jurídica como un bien fundamental, esto es, necesario para satisfacer una necesidad vital del ser humano" (2011: 219). Siendo así, la seguridad es un bien jurídico que satisface una necesidad de la persona física, conceptualizando al bien jurídico como aquel ente que, debidamente tutelado, garantizado y protegido por el Derecho, es fundamental para la realización plena del ser humano al interior de la sociedad.

Por otra parte, la seguridad jurídica es un elemento polifacético que se relaciona con los ámbitos: racional, étnico, técnico, positivo y sociológico del Derecho. De esta forma, el Derecho debe aspirar a realizar otros valores adicionales a la justicia y el bien común, pero íntimamente relacionados entre sí, como por ejemplo la seguridad jurídica, mediante la cual recrea en la sociedad un ambiente favorable y las condiciones adecuadas para que una persona desarrolle normalmente sus actividades, en la convicción de que si estas cumplen con ser licitas, serán respetadas por el Estado.

De esta manera, la existencia del valor de la seguridad jurídica constituye una garantía otorgada por el Estado a los individuos de que cada persona puede ejercer su derechos individuales con libertad y responsabilidad, sin el riesgo de que abruptamente el marco jurídico cambie y establezca nuevas condiciones para ese ejercicio. En otras palabras, la seguridad jurídica 

Jorge Núñez Grijalva

consiste en la realización plena del orden jurídico positivo y apropiado, para la sociedad que rige.

\subsection{Presencia de los valores de la justicia y la seguridad jurídica, en la normativa penal ecuatoriana regulatoria de la competencia desleal}

En el año 1998, el Congreso Nacional del Ecuador promulgó la Ley de Propiedad Intelectual, la cual posteriormente fue codificada y promulgada mediante el R.O. 426 del 28 de diciembre de 2006. Esta norma, en sus artículos del 319 al 331, tipificaba varios delitos contra la propiedad intelectual y sus diversas formas, considerados como actos de competencia desleal, aquellos tipificados y procesados mediante la aplicación del Código de Procedimiento Penal y, de ser el caso, sancionados aplicando la misma Codificación de la Ley de Propiedad Intelectual (en adelante, CLPI). La iniciativa procesal para perseguir de oficio estas infracciones, la tenía la Fiscalía General del Estado, según lo dispuesto en el Art. 328 de la CLPI, al ser las mismas consideradas infracciones "de acción pública y de instancia oficial."

Sin embargo, en el año 2014 se promulgó el nuevo COIP, el cual reemplazaba a los anteriores Código Penal y Código de Procedimiento Penal, y además mediante su Disposición Derogatoria Vigésimo Segunda, daba de baja los artículos del 319 al 331, y el segundo inciso del artículo 342 de la CLPI. De esta manera, el Legislador pretendía que el COIP abarcase de manera holística, el espectro general de todos los ámbitos de infracciones penales posibles y la tipificación de cada acto específico (delito o contravención) en el país, y además, las vías procesales para su tratamiento y sanción. Es decir, el legislador pretendía que la nueva ley, sea una norma sustantiva y adjetiva a la vez (integral).

No obstante, posiblemente por la prisa que tuvo la Asamblea Nacional en promulgar la nueva ley (en base a los intereses políticos del momento), el Legislador derogó el articulado supra mencionado relativo a los actos de competencia desleal contenidos en la CLPI, y aparentemente "se olvidó" de reemplazarlo por un articulado similar en el texto del nuevo COIP, dejando de esta forma un importante vacío legal en el país. En la práctica, este vacío normativo provocó que una vez en vigencia el nuevo COIP, no sea posible perseguir penalmente ninguna clase de delitos de competencia desleal, ya que como se conoce, no se puede seguir una acción penal contra delitos no tipificados en el texto de la norma pertinente.

Ante los reclamos generalizados provenientes sobre todo de los colegios de abogados de Ecuador y de los profesionales en libre ejercicio no agremiados, el Legislador ecuatoriano se vio presionado para reformar el recién promulgado COIP. Es así como con fecha 30 de septiembre de 
2015, mediante el R.O. 598, se promulgó la Ley Orgánica Reformatoria del Código Orgánico Integral Penal, la cual procuraba enmendar las diversas omisiones y errores que había provocado la innecesaria prisa legislativa. En lo referente al combate contra los delitos de competencia desleal, esta ley reformatoria, mediante su Art. 3, incorporó en el texto del COIP, el Art. 208 A.

Sin embargo, cabría decir que en este caso "el remedio fue peor que la enfermedad", ya que nuevamente por la prisa en presentar la reforma solicitada, el Legislador incorporó al texto de la ley solo tres tipos penales relativos a la regulación de la competencia desleal, y se olvidó de hacerlo con el resto de prácticas de esta clase contenidas en las normas no penales, como por ejemplo la Ley Orgánica de Regulación y Control del Poder del Mercado, la cual como ya se mencionó regula desde el Derecho Económico a 29 clases diferentes de actos de competencia desleal, lo cual por supuesto se muestra como una situación jurídica totalmente adversa. Pero esto no es todo; la situación empeora cuando revisamos las acciones procesales para sancionar esta clase de delitos.

Así, el Art. 208 A del COIP contempla la posibilidad de sancionar pecuniariamente a la persona que fabrique o comercialice, mercancías que en su envoltorio contengan, sin la respectiva autorización, una marca idéntica a otra válidamente registrada para tales mercancías, disponiendo que el valor mínimo a considerar de la mercadería incautada, para considerarlo infracción penal sea el equivalente a 142 SBUTG, lo que a la fecha significaría USD 56.8009. En este caso, de comprobarse el delito luego de haberse aplicado el debido proceso judicial, se podría aplicar una multa de 155 a 185 SBUTG, es decir, a la fecha esta multa oscilaría entre USD 62.000 a USD 74.000. Sin embargo, en la práctica, ¿qué sucede con las infracciones de esta clase, que no alcancen los USD 56.800?

$\mathrm{Al}$ respecto, sucede que en estricta aplicación del principio de legalidad contenido en el Art. 226 de la Constitución de la República, y, dado que en el Derecho Penal no se permite la interpretación extensiva de las normas, en la práctica es usual que estos actos de competencia desleal no alcance a ser juzgados, quedando en la impunidad por insuficiencia normativa, ya que la Fiscalía General del Estado generalmente se inhibe de conocer los mismos cuando no llegan al valor mínimo tipificado por la Ley para procesarlos penalmente.

En base a la situación normativa antes descrita, y en lo relativo a la presencia de los valores jurídicos de justicia, bien común y seguridad jurídica, los operadores de justicia no podrán investigar ni procesar la mayor parte de las infracciones penales que se presenten por esta causa, quedando los hechos y sus autores en la impunidad, la cual como es evidente representa la antítesis de la justicia. 


\section{Valores jurídicos en la Regulación Penal de la Competencia Desleal en Ecuador}

De otra parte, el COIP y su Art. 208 A, tampoco les otorga a los operadores de justicia (fiscales y jueces penales) las herramientas procesales adecuadas y suficientes para combatir los delitos de competencia desleal, ya que al poner un piso mínimo en el monto de los perjuicios causados por estas infracciones, dejan fuera del alcance procesal penal a gran cantidad de actos de competencia desleal. Por lo expuesto, no se observa la real y efectiva presencia del valor jurídico de la justicia en la normativa penal ecuatoriana regulatoria de la competencia desleal.

Respecto al valor jurídico del bien común, de forma similar a lo ocurrido con el valor justicia, y en base a la falta de tipificación en el COIP de la mayor parte de actos de competencia desleal, y a la existencia de pisos mínimos de daños económicos para poder procesar estos delitos, tampoco se puede considerar que, en la práctica, exista presencia del valor del bien común en la normativa penal ecuatoriana relativa al combate contra la competencia desleal.

En lo referente al valor de la seguridad jurídica, la situación es peor, debido a que cuando el Legislador ecuatoriano derogó mediante el nuevo COIP, las normas que permitían el procesamiento penal de los actos de competencia desleal (contenidas en la anterior CLPI), y por descuido u olvido no las reemplazó oportunamente por un nuevo articulado equivalente, fácticamente envió a la comunidad nacional e internacional una imagen de descuido (por decir lo menos) respecto al tratamiento jurídico que el país le otorga a la regulación de la competencia desleal.

Evidentemente esta situación no puede seguir adelante, ya que desde la entrada en vigor del COIP ha disminuido notablemente la posibilidad de combatir penalmente los delitos de competencia desleal, que surjan como resultado de la cada vez más intensa dinamia de los mercados.

Además, ética y moralmente, la situación antes descrita deja en duda la presencia efectiva de los valores jurídicos, objeto de estudio, en la norma penal ecuatoriana, ya que, de aplicarse los principios generales del Derecho, como los de buena fe e igualdad ante la ley, toda persona que cometa esta clase de infracción debería ser imputada y de ser el caso procesada y sancionada.

Resulta de importancia resaltar que, el dejar sin sanción adecuada a los delitos de competencia desleal, por la no presencia de los valores jurídicos citados en la norma positiva penal, ciertamente genera un daño moral mayúsculo a la sociedad, anticipando la posibilidad de que esta le pierda confianza al sistema jurídico en sí mismo.

Para enmendar esta situación, sería deseable que se produzca en un tiempo razonable una nueva reforma (segunda) del COIP, que regrese las cosas a su estado normal y necesario. A manera de simples criterios orientadores, los cambios sugeridos podrían tener relación con: 
a. El restablecimiento de la concordancia entre el Código Orgánico Integral Penal -COIP y la Ley Orgánica de Regulación y Control del Poder de Mercado -LORCPM, incorporando al COIP, todos los tipos de infracciones tipificadas como actos de competencia desleal en la LORCPM, para su control y procesamiento penal.

b. La supresión, en el Art. 208A del COIP del piso mínimo de 142 SBUTG, para poder procesar penalmente a quienes incurran en infracciones contra la competencia desleal.

Finalmente, y a manera de justificación de las posibles reformas propuestas para el COIP, es bienvenido el pensamiento de Roxin, quien a propósito del sistema normativo penal se preguntaba lo siguiente: "¿dde qué sirve la solución de un problema jurídico, que a pesar de su hermosa claridad y uniformidad es, desde el punto de vista político criminal, erróneo?” (2000: 19); lo cual además se complementa con las ideas de Rawls, para quien la justicia es un tema preeminente en toda sociedad, y en el camino hacia su búsqueda "no importa que las leyes e instituciones están ordenadas y sean eficientes: si son injustas han de ser reformadas o abolidas" (1979: 19).

\section{Conclusiones}

Una renovada relectura hermenéutica de los cuerpos normativos a nuestra disposición, efectuada en la presente investigación, ha permitido identificar las limitaciones objetivas en términos de los "déficits axiológicos" existentes en los procesos de regulación penal de la competencia desleal en Ecuador, en base a lo cual se concluye que:

a. El Código Orgánico Integral Penal -COIP ecuatoriano, y sus posteriores reformas legislativas, no evidencian la presencia real de los valores cardinales de la justicia, el bien común y la seguridad jurídica, en las normas encargadas de la regulación y protección de los derechos fundamentales de las personas contra los diversos actos de competencia desleal.

b. La vigente legislación penal del país, no contempla la tipificación completa de todos los posibles actos de competencia desleal, situación claramente reñida con la necesidad jurídica - social de que, en un Estado con una Constitución garantista de derechos fundamentales, se alcancen los valores de justicia, bien común y seguridad jurídica.

c. Se hace necesaria una reforma al Código Orgánico Integral Penal ecuatoriano-COIP, la cual a través de incorporar al mismo los valores de la justicia, bien común y seguridad jurídica, permitan que el marco regulatorio nacional disponga de normas más efectivas para 
Jorge Núñez Grijalva
$38 \quad$ Valores jurídicos en la Regulación Penal de la Competencia Desleal en Ecuador

la regulación y sanción de los diversos actos de competencia desleal que se presenten en la vida social del país.

\section{Referencias Bibliográficas}

ASAMBLEA NACIONAL DEL ECUADOR. 2016. Código Orgánico de la Economía Social de los Conocimientos, Creatividad e Innovación. R.O. N.- 399, o9 de diciembre de 2016. Quito, Ecuador.

ASAMBLEA NACIONAL DEL ECUADOR. 2015. Ley Orgánica Reformatoria del Código Orgánico Integral Penal. R.O. 598, 30 de septiembre de 2015. Quito, Ecuador.

ASAMBLEA NACIONAL DEL ECUADOR. 2014. Código Orgánico Integral Penal. R.O. 180, 10 de febrero de 2014, reformado 30 de septiembre de 2015. Quito, Ecuador.

ASAMBLEA NACIONAL DEL ECUADOR. 2011. Ley Orgánica de Regulación y Control del Poder del Mercado. Registro Oficial N.- 555, del 13 de octubre de 2011. Última modificación 12 de septiembre de 2014. Quito, Ecuador.

ASAMBLEA NACIONAL CONSTITUYENTE. 2008. Constitución de la República del Ecuador. R.O. 449, 20 de octubre de 2008, última modificación, 21 de diciembre de 2015. Montecristi. Quito, Ecuador.

BEDOYA, María Roscio. 2011. Métodos de interpretación del derecho en el constitucionalismo contemporáneo. En: Estudios de Derecho; Medellín. Tomo68,N. ${ }^{0}{ }_{151}$,(Jun2011):pp. 293-315. Disponibleenlínea.En:https:// search-proquest-com.pucesa.idm.oclc.org/docview/1238989145/ fulltextPDF/6F66DA513B34B3FPQ/3?accountid=13357. Fecha de consulta: 14 de febrero de 2018.

CONGRESO NACIONAL DEL ECUADOR. 1998. Ley de Propiedad Intelectual. R.O. 320, 19 de mayo de 1998. Quito, Ecuador.

DE AZCÁRATE, Patricio. 1873. Obras Filosóficas de Aristóteles. Vol.1, Moral a Nicómaco, Libro V, Teoría de la Justicia. Medina y Navarro Editores. Madrid, España.

ESTRADA, Sergio. 2011. La noción de principios y valores en la jurisprudencia de la Corte Constitucional. En: Revista Facultad de Derecho y Ciencias Políticas, vol. 41, n.- 114. Pp. 41-76. Universidad de Medellin. Medellin, Colombia. 
HART, Herbert. 1983. Essays in Jurisprudence and Philosophy. Clarendon Press. Oxford University. Oxford, England.

ROBERT S. HARTMANN INSTITUTE. 2017. ¿Quién fue Robert S. Hartmann? Robert S. Hartmann Institute, Rama Latinoamérica. Disponible en línea. En: http://www.hartmaninstitute-la.com/?page_id=33. Fecha de consulta: 29 de junio de 2017.

KELSEN, Hans. 1991. ¿Qué es la Justicia? Traducido por CALVERA, Leonor. Ed. Leviatán. Buenos Aires, Argentina.

KRIEGEL, Alberto; KRIEGEL, Mauricio. 1889. Instituta, Libro I, Título I, De la justicia y el Derecho, de César Flavio Justiniano. Traducido al Castellano por GARCÍA DEL CORRAL, Ildefonso. Ed. Jaime Molinas. Barcelona, España.

MICHELINI, Dorando. 2007. Bien común y ética pública. Alcances y límites del concepto tradicional de bien común. En: Tópicos Revista de Filosofía de Santa Fe, número -15, enero-diciembre 2007. Pp. 37-54 Santa Fe. Disponibleen línea. En: http://www.scielo.org.ar/scielo.php?script=sci arttext\&pid=S1666-485X2007000100002. Fecha de consulta: 2 de julio de 2017.

NEGRETE, Edward. 2016. Aspectos procesales de la competencia desleal. En: Revista Justicia Juris, 2016, vol.12, n.1. Pp. 56-64. Univ. Autónoma del Caribe. Barranquilla, Colombia.

RODRÍGUEZ - TOUBEZ, Joaquín. 1993. El iusnaturalismo de John Finnis. En: Anuario de Filosofía del Derecho, X. Sociedad Española de Filosofía Jurídica y Política, Ministerio de Justicia, Agencia Estatal Boletín Oficial del Estado, Madrid. Disponible en línea. En: https://dialnet.unirioja.es/ servlet/articulo?codigo=142246. Fecha de consulta: 1 de julio de 2017 .

OTAMENDI, Jorge. 1998. La competencia desleal. En: Revista Jurídica Universidad de Palermo, Año 3, N.- 2, Pp. 1-44. Buenos Aires. Disponible en línea. En: http://www.palermo.edu/derecho/publicaciones/pdfs/ revista_juridica/n3N2Octubre1998/032Juridica01.pdf. Fecha de consulta: 24 de noviembre de 2017.

ORGANIZACIÓN MUNDIAL DE LA PROPIEDAD INTELECTUAL. 1883. Convenio de París para la protección de la propiedad industrial. Enmendado el 28 de septiembre de 1979. OMPI. Ginebra, Suiza.

ORGANIZACIÓN MUNDIAL DE LA PROPIEDAD INTELECTUAL -OMPI. 1994. Protección contra la competencia desleal, análisis de la situación mundial actual. Oficina Internacional de la Organización Mundial de la Propiedad Intelectual -OMPI-. Ginebra. Disponible en línea. En: ftp:// 
Jorge Núñez Grijalva
$40 \quad$ Valores jurídicos en la Regulación Penal de la Competencia Desleal en Ecuador

ftp.wipo.int/pub/library/ebooks/wipopublications/WIPO_PUB_725s. pdf. Fecha de consulta: fecha 25 de noviembre de 2016.

PONTIFICIO CONSEJO JUSTICIA Y PAZ. 2004. Compendio de la doctrina social de la Iglesia, núm. 164, El principio del bien común. Ciudad de El Vaticano. Disponible en línea. En: http://www.vatican.va/roman_ curia/pontifical_councils/justpeace/documents/rc_pc_justpeace_ doc_20060526_compendio-dott-soc_sp.html\#Significado\%20y\%20 aplicaciones\%2oprincipales. Fecha de consulta: 1 de julio de 2017.

PORTELA, Jorge.2008. Una introducción a los valores jurídicos. Cátedra Internacional Ley Natural y Persona Humana, Facultad de Derecho de la Pontificia Universidad Católica Argentina. Ed. Rubinzal - Culzoni. Buenos Aires, Argentina.

PUYOL. Ángel. 2004. La herencia igualitarista de John Rawls. En: Revista de Filosofía Moral y Política Isegoría, N.- 31. Pp. 115-130. Instituto de Filosofía, Consejo Superior de Investigaciones Científicas. Madrid, España.

RAWLS, John. 1999. A Theory of Justice, Revised Edition. Ed. The Belknap press of Harvard University press. Cambridge, Estado Unidos de América.

RAWLS, John. 1979. Teoría de la justicia. Fondo de Cultura Económica. México DF., México.

RAWLS, John. 1958. "Justice as Fairness". En: Philosophical Review, n.- 67, Abril 1958. Pp. 164-194. CornellUniversity. New York, EE. UU.

ROXIN, Claus. 200o. Política criminal y sistema del Derecho penal. Traducción de MUÑOZ, Francisco, 2ed. Ed. Hammurabi. Buenos Aires, Argentina.

SAMUELSON, Paul; NORDHAUS, William. 1998. Economía. Traducción de la XV ed. Ed. McGraw Hill. Madrid, España.

SANTO TOMÁS DE AQUINO. 1225-1274. Suma Teológica, Partes I y II, Cuestión 98, La Ley Antigua. Disponible en línea. En: http://hjg.com.ar/ sumat/b/c98.html. Fecha de consulta: 2 de Julio de 2017.

SMITH, Adam. 1776. Investigación de la naturaleza y causas de la riqueza de las naciones, Libro I, Cap. II. Traducido al Castellano por ALONSO ORTÍZ, Josef. 1794. Ed. Oficina de la Viuda e Hijos de Santander. Valladolid, España.

STIGLITZ, Joseph. 2002. El malestar en la globalización. Ed. Taurus. Bogotá, Colombia. 
SUPERINTENDENCIA DE INDUSTRIA Y COMERCIO DE COLOMBIA-SIC. 2001. Concepto 01086015, núm. 2. Bogotá. Disponible en línea. En: http://www.sic.gov.co/recursos_user/historico/d2011sic7933.htm Fecha de consulta: 9 de diciembre de 2016.

TAPIA, Mauricio. 2008. La Ley $\mathrm{N}^{\circ} 20.169$ sobre Competencia Desleal: una hipótesis de responsabilidad civil contractual. En: Cuadernos de Análisis Jurídico. Regímenes especiales de responsabilidad. Colección de Derecho Privado, vol. Iv, Ed. Universidad Diego Portales, Santiago de Chile, Chile.

VIDAL, Ma. Carmen. 2001. La defensa de la competencia y la competencia desleal, Revista Offarm, Vol. 20. Núm. 6. junio 2001, Pp. 164-172. Disponible en línea. En: http://www.elsevier.es/es-revista-offarm-4articulo-la-defensa-competencia-competencia-desleal-13015498. Fecha de consulta: 22 de enero de 2018.

ZAVALA, Jorge. 2011. Teoría de la seguridad jurídica. En: Revista de Derecho Iuris Dictio, Vol. 12, núm. 14, 2011, Universidad San Francisco. Quito. Pp. 219. Disponible en línea. En: http://revistas.usfq.edu.ec/index.php/ iurisdictio/article/view/709/781. Fecha de consulta: 1 de julio de 2017. 
Vol. 39 N $^{\circ} 69$

Esta revista fue editada en formato digital y publicada en julio de 2021, por el Fondo Editorial Serbiluz, Universidad del Zulia. Maracaibo-Venezuela 